\title{
Spontaneous Remission of a Big Subligamentous Extruded Disc Herniation: Case Report and Review of the Literature
}

\author{
Veli Çitişli, Muhammet İbrahimoğlu \\ Department of Neurosurgery, Pamukkale University School of Medicine, Denizli, Turkey
}

Spontaneous Regression of a Big Subligamentous Extruded Disc Herniation: Case Report And Review of The Literature The most efficient method for the treatment of lumbar disc herniation is still controversial. The most important aspect is the application of the suitable conservative or surgical treatment to the right patient at the right time. In lumbar disc herniation patients, one must not precipitate except for cases that require surgical indications as in cauda equina syndrome, evolutive motor deficit and persistence of pain in spite of the narcotics. However, the spontaneous regression mechanism has not been completely determined yet. The proposed hypotheses are; dehydration, retraction of the disc to the hernia in the annulus fibrosis, enzymatic catabolism and phagocytosis. In this study, the case of a patient with huge lumbar disc hernia regressing by itself has been presented and the potential mechanisms of disc regression have been discussed.

Key Words: Intervertebral disc hernia $\cdot$ Conservative treatment $\cdot$ Magnetic resonance imaging $\cdot$ Spontaneous regression

\section{INTRODUCTION}

Lumbar disc hernia is a frequently observed disease accompanied by lumbo and radiculopathy ${ }^{5}$. Radicular pain has been described for the first time by Dandy in 1929 as a clinical syndrome due to the extradural mass". Mixter and Barr have proposed in 1934 that the extruded material may lead to sciatic pain and have described the surgical intervention to perform on the disc ${ }^{1}$. In literature, there are many studies showing the regression of huge disc hernia without surgical intervention ${ }^{5,8,13)}$.

One of the most frequently observed diseases in spine is lumbar disc hernia. The correct patient selection is the most important factor affecting the result in lumbar disc surgery ${ }^{5}$. The priority treatment for lumbar disc hernia is conservative and neurological deficit, cauda equina syndrome are definitive surgical indications. Especially in disc hernia for lumbar regions, spontaneous regression is frequent and presents an $85 \%$ improvement in approximately 6 weeks ${ }^{11)}$. Spontaneous disc regression

\footnotetext{
- Received: December 15, 2014 • Revised: January 8, 2015

- Accepted: January 24, 2015

Corresponding Author: Veli Çitişli, MD

Department of Neurosurgery, Pamukkale University Medical Faculty, 20070 KInIKII-DENIZLLI, TURKEY

Tel: +90-258-444-07-28, Fax: +90-258-296-17-65

E-mail: vcitisli@gmail.com

$\otimes$ This is an Open Access article distributed under the terms of the Creative

Commons Attribution Non-Commercial License (http://creativecommons.org/ licenses/by-nc/3.0/) which permits unrestricted non-commercial use, distribution, and reproduction in any medium, provided the original work is properly cited.
}

is observed sometimes and is one of the important topics ${ }^{5)}$. In our study, the spontaneous disc regression of a patient with huge lumbar disc hernia has been discussed in parallel with literature.

\section{CASE REPORT}

A fifty five year old female patient has applied to the polyclinic for backache and bilateral leg pain that developed upon stretching. The patient has been examined and has been evaluated together with a recently performed lumbar magnetic resonance imaging (MRI) film. It has been determined that she can be operated according to the complaints. However, as the patient said that a lumbar MRI has been performed 6 months ago, this film has also been evaluated. The patient has applied to another neurosurgery clinic for severe backache and bilateral leg pain 6 months ago and a surgical intervention has been proposed upon the diagnosis of sub-ligamentous huge disc hernia narrowing the spinal channel in the middle line at the L5-S1 disc in lumbar MRI (Fig. 1A, B). The patient who did not accept the operation and who affirmed that the pain has disappeared with medical treatment and physiotherapy has applied to our polyclinic for backache and leg pain. No pathology has been observed in the routine analyses performed. In neurological examination, the straight leg abduction test was free, and no motor and sensitive deficit has been detected. Her reflexes were normoactive. It has been observed on the new lumbar MRI that the disc hernia located at the L5-S1 disc interval has regressed spontaneously (Fig. 1C, D). It has 


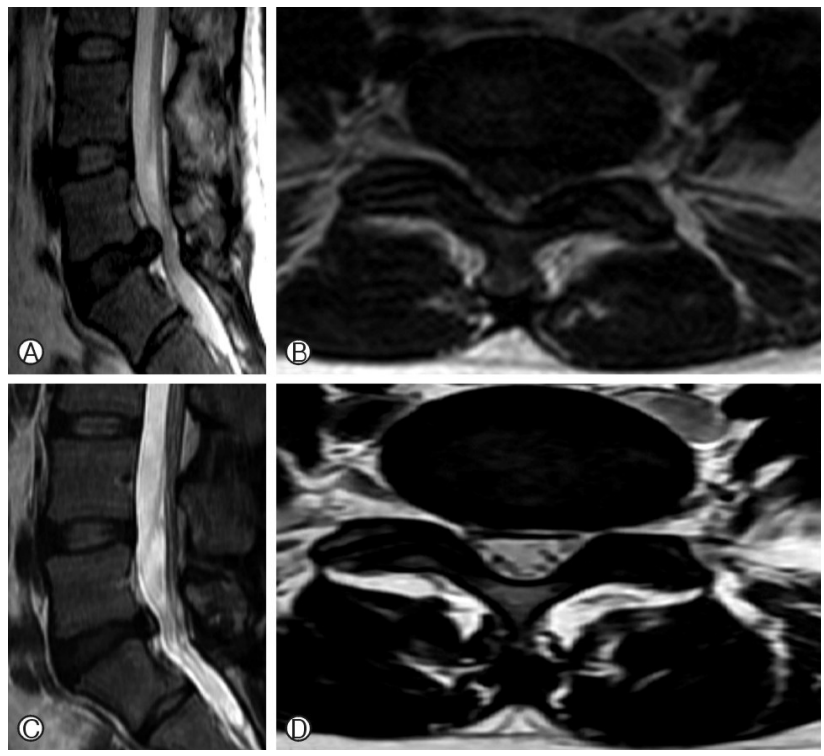

Fig. 1. In $A$ (sagittal) and $B$ (axial), a central subligamentous huge discopathy dural bag has been observed in T2 in the MRI performed in the first application of the patient and a pressure has been detected in the bilateral $\mathrm{S} 1$ nerve root. $\ln \mathrm{C}$ and $\mathrm{D}$, a regression has been observed in control lumbar MRI.

been decided to perform a medical treatment and necessary recommendations have been proposed.

\section{DISCUSSION}

Disc hernia is one of the most frequent cause of radicular pain and backache. The spontaneous disc regression is usually in direct relation with clinic improvement and shall be confirmed with MRI images ${ }^{5)}$.

Although the spontaneous regression of non-operated symptomatic disc hernia has been proposed, the mechanism has still not been determined clearly. First information about the spontaneous regression of disc hernia has been proposed in the 1980 by Guinta et al. ${ }^{3)}$. Many papers have been published about this disease ${ }^{12)}$.

Various hypotheses have been proposed about spontaneous disc regression. These have been described as dehydration, resorption with macrophage phagocytosis, retraction theory with the retraction of posterior longitudinal ligament, disc degeneration, and immunological reaction ${ }^{5,7}$.

In dehydration which is the first mechanism used to explain the spontaneous disc regression; the signal intensity of nucleus pulposus at the beginning of the hernia is higher than in original nucleus, and then it decreases with time, the hydration of nucleus pulposus at the beginning of the herniation is then rapidly followed by the dehydration of the nucleus pulposus?
As a result, nucleus pulposus loses water with time and then disappears by shrinking. The second mechanism is the resorption theory. The nucleus pulposus with hernia is considered as a foreign body by the body and the inflammatory process starts with neovascularization. The nucleus pulposus with hernia eliminated with enzymatic catabolism and phagocytosis. The third theory is the retraction theory with the retraction of the posterior longitudinal ligament. In herniation that is associated with the disc interval, it is the disappearing of disc material after the negativation of the pressure within the intradiscal space. The treatment modalities permitting the decrease of the intradiscal pressure in disc patients operate using this mechanism.

The type of disc herniation for spontaneous disc regression is more important than the dimensions of disc hernia. Moreover, there are studies defending that the presence of a transligamentous prolongation of the disc material with herniation is more important than sub-ligamentous and sequestrated herniation ${ }^{5}$. As well as studies proposing that the radiographic observations made on patients with sequestrated disc hernia show that this is more likely to undergo regression more rapidly compared to the other disc herniation sub-types ${ }^{14)}$. In this study, it is possible to propose the regression as an inflammatory response against the free fragment. In addition, it has been declared in literature that even disc hernias that migrate to posterior epidural interval may undergo spontaneous regression ${ }^{4}$. The largest series about the regression of disc hernia in literature are those of Martínez-Quiñones et al. ${ }^{7}$. In this study including 858 patients, the spontaneous disc regression in 33 patients has been detected by MRI ${ }^{11)}$. In patients with sequestrated disc herniation and severe radicular pain, the regression of disc herniation shall be regularly monitored clinically and radiologically. The regression of sequestrated discs in these patients has been shown by 3-6 weeks monitoring and the control MRI performed between month 4 and 9 in a study of Orief et al..$^{10}$. Moreover, there are also studies showing that the disc has regressed and that the patient has got better by conservative treatment in patients with huge disc herniation as in our patient ${ }^{2}$.

In the neurological examination of our patient, we have evaluated the straight leg abduction, motor and sensitive examination, deep tendon reflexes, the presence of atrophy and pathological reflexes. Straight leg abduction test is frequently observed in lumbar disc degeneration and spinal stenosis associated with lumbar disc degeneration ${ }^{13)}$. We have used MRI for radiological examination in addition to routine laboratory analyses. The leucocyte, sedimentation, $\mathrm{C}$ reactive protein $(\mathrm{CRP})$ and rheumatoid factor $(\mathrm{RF})$ values of our patient were normal. Lumbar MRI observations supporting disc degeneration and dehydration were obtained in our patient. Usually 
accepted by everyone, disc herniation begins with disc degeneration, and most discs with herniation on T2 weighted MRI show 'black disc' low signal. Disc has pre- sented a hypointense aspect in all the T2 sections. These results have supported the dehydration of the disc. And this was compatible with spontaneous regression.

\section{CONCLUSION}

Although the spontaneous regression of disc hernia is a rare situation, it has been shown in many studies. However, data are limited to explain the spontaneous regression in lumbar disc disease. It is impossible to deny that the detection and the monitoring of the spontaneous regression of lumbar discopathy is possible using MRI. The loss of intensity in T2 sections in MRI supports the dehydration. No matter how the dimension of lumbar disc hernia is important, conservative treatment shall be preferred in patients with slight or middle neurological symptoms and observations, and shall be priority treatment 3-6 weeks before the surgery.

\section{REFERENCES}

1. Dandy WE: Loose cartilage from intervertebral disk simulating tumor of the spinal cord. By Walter E. Dandy, 1929. Clin Orthop Relat Res 238:4-8, 1989

2. Gezici AR, Ergün R: Spontaneous regression of a huge subligamentous extruded disc herniation: short report of an illustrative case. Acta Neurochir (Wien) 151:1299-1300, 2009
3. Guinto FG, Hashim H, Stumer M: CT demonstration of disk regression after conservative therapy. AJNR 5:632-633, 1984

4. Henmi T, Sairyo K, Nakano S, Kanematsu Y, Kajikawa T, Katoh $S$, et al: Natural history of extruded lumbar intervertebral disc herniation. J Med Invest 49:40-43, 2002

5. Kim SG, Yang JC, Kim TW, Park KH: Spontaneous regression of extruded lumbar disc herniation: three cases report. Korean J Spine 10:78-81, 2013

6. Macki M, Hernandez-Hermann M, Bydon M, Gokaslan A, McGovern K, Bydon A: Spontaneous regression of sequestrated lumbar disc herniations: Literature review. Clin Neurol Neurosurg 120:136-141, 2014

7. Martínez-Quiñones JV, Aso-Escario J, Consolini F, Arregui-Calvo R: Spontaneous regression from intervertebral disc herniation. Propos of a series of 37 cases. Neurocirugia (Astur) 21:108-117, 2010

8. Mixter WJ, Barr JS: Rupture of the intervertebral disc with involvement of the spinal cord. New Engl J Med 211:210-215, 1934

9. Monument MJ, Salo PT: Spontaneous regression of a lumbar disk herniation. CMAJ 19:183-188, 2011

10. Orief T, Orz Y, Attia W, Almusrea K: Spontaneous resorption of sequestrated intervertebral disc herniation. World Neurosurg 77:146-152, 2012

11. Ribeiro RP, Matos RM, Vieira A, Costa JM, Proença R, Pinto R: Spontaneous regression of symptomatic lumbar disc herniation. Acta Reumatol Port 36:396-398, 2011

12. Ryu SJ, Kim IS: Spontaneous Regression of a Large Lumbar Disc Extrusion. J Korean Neurosurg Soc 48:285-287, 2010

13. Slavin KV, Raja A, Thornton J, Wagner FC Jr: Spontaneous regression of a large lumbar disc herniation: report of an illustrative case. Surg Neurol 56:333-336, 2001

14. Tarukado K, Ikuta K, Fukutoku Y, Tono O, Doi T: Spontaneous regression of posterior epidural migrated lumbar disc fragments: case series. Spine J 13:981-988, 2013 